\title{
Comparative study between Oxytocin Versus Tranexamic Acid and Ethamsylate to reduce blood loss intra-operative and post-operative during the Elective Cesarean Section.
}

\author{
AbdelAzim S. Mohamed, ${ }^{1}$ M.B.B.CH, AbdelSattar Farhan, ${ }^{1}$ MD, Ahmed Alsheikh, ${ }^{1}$ MD.
}

\section{* Corresponding Author: \\ AbdelAzim Sobhi \\ abdopasha@gmail.com}

Received for publication March 21, 2020; Accepted May 6, 2021; Published online May 7, 2021.

\section{Copyright 2020 The Authors published by Al-Azhar} University, Faculty of Medicine, Cairo, Egypt. All rights reserved. This an open-access article distributed under the legal terms, where it is permissible to download and share the work provided it is properly cited. The work cannot be changed in any way or used commercially.

doi: 10.21608/aimj.2021.61234.1439.

${ }^{1}$ Obstetrics and Gynecology Department, Faculty of Medicine, Al-Azhar University, Cairo, Egypt.

\begin{abstract}
Background: Delivery bleeding is still a major catastrophe that facing most of obstetricians, leading to global maternal exhaustion and fatality. So estimation of the blood loss and the changes occurring during the procedure are important in the management of the bleeding.

Aim of the study: : Comparing loss of blood during Cesarean Delivery, Intra and post-operative in parturients, injected by Oxytocin versus Tranexamic acid with Ethamsylate.

Patients and Methods: Blinded randomized controlled trial, whereas 200 of Gravid women shared and equally distributed to double collections, each collection includes 100 of women and Each of them is injected with Syntocinon 5 IU infusion on 500 cc saline $0.9 \%$, at rate of $100 \mathrm{~cm} /$ hour Or Tranexamic acid with Ethamsylate, 5 to $10 \mathrm{~min}$ IV slowly before the abdominal delivery, with evaluation of the bleeding amount.

Results: Blood loss amount, participants requiring for blood transfer OR more intervention, were minimal in the tranexamic acid and ethamsylate collection than in the oxytocin collection. Moreover the results of hemoglobin and hematocrit postoperatively were elevated in the participants who injected by both tranexamic acid and ethamsylate comparing with the participants who injected by the Syntocinon.

Conclusion: The Evaluated variables with the positive and negative results of the research medications, demonstrated the following: Both Tranexamic acid and Ethamsylate could be effective than Oxytocin in minimizing the demand for blood transfer, with the stability of both hematologic profile and the hemodynamics. And both too, appear to be safe and efficient option in the management of the abdominal delivery.

Keywords: Intra-operative and postoperative bleeding; Blood Loss; Elective Cesarean Delivery; Oxytocin; Tranexamic acid; Ethamsylate.
\end{abstract}

Disclosure: The authors have no financial interest to declare in relation to the content of this article. The Article Processing Charge was paid for by the authors.

Research Support: RCT approval numbers: NCT04656067 and PACTR202101794541918

Authorship: All authors have a substantial contribution to the article.

\section{INTRODUCTION}

Abdominal Delivery is a procedural contribution to save the life's of the fetus or the mother through incisions of the abdomen and lower uterine segment after viability. ${ }^{1}$

It is frequently significant when the vaginal labour would situate the baby or the mother in danger. ${ }^{2}$ this could be of obstructed vaginal labour, twins pregnancy, increased vital marks of the mother, breech labour or problems with the placenta Or the umbilical cord and the pelvic area of the conceived woman or history of a previous C-delivery. ${ }^{2}$

The World Health Organization advocates that abdominal delivery should be performed only if medically obligatory. ${ }^{3}$ Some Cesarean Deliveries are done by medically of non-cause which is revealed upon request by another one, oftenly the mother. ${ }^{2}$

Postpartum bleeding or After Delivery Bleeding is still a serious condition of maternal exhaustion and fatality world-widely corresponding to more or less $25 \%$ of dying of mothers directly. ${ }^{4}$ and reveals for fifty percent $(50 \%)$ of women fatality in developing countries . ${ }^{5}$

Many plans of action were set to decrease the intraoperative blood loss, and ready to give help in reducing the hazards of blood transfer and therefore the post-procedure morbidity of the women ${ }^{6}$

Drugs for example Sytocinon, Carbetocen, Mesoprostol, Prostaglandin-F2 alpha, and 
methylergonovin (methargine).were tested previously to adjust hemorrhage incidence through and after the Abdominal Delivery (RCOG 2016). ${ }^{7}$

Oxytocin: The Obstetricians and Gynecologists of the Royal College rules that the abdominal delivery still emphasis about injection of slow intravenous dose of $5 \mathrm{IU}$ from the oxytocin after fetal labour to urge contractions of the uterus, and hence, decrease intra-operative blood loss and thereby Postpartum Bleeding. $^{7}$

Tranexamic acid (Kapron) seems to be an artificially made drug resemble the structure of Lysine which is one of the amino-acids . It works in a role of anti-fibrinolysis effect by reversible way, by attaching 4 to 5 lysine receptor sites on plasminogen. Furthermore suppresses the action of plasmin which has direct low capacity $($ IC50 $=87 \mathrm{mM}){ }^{8}$ and it can prevents the effective location urokinase plasminogen activator (uPA) with higher selectivity $(\mathrm{Ki}=2 \mathrm{mM})$ between all the serine proteases ( $\mathrm{Wu}$ G. et a.l, 2018). ${ }^{9}$

Etamsylate (Dicynon) this drug is a haemostatic agent its action depends on elevation the capillary endothelial resistancy and motivating adherence(coherence) of the platelets. ${ }^{10}$ It likewise hinders bio-syntheses and activity on these prostaglandin products which as a reason for platelets separations, dilatation of the blood vessels and widened the permeability of the small vessels. ${ }^{11}$, It also facilitates platelet aggregation and adhesion which at last induce decrease and stop of hemorrhage. $^{12}$

\section{PATIENTS AND METHODS}

This study was conducted between April and October 2020, on 200 conceived women attending to Sayed Galal Hospital, Al Azhar University and Shoubra General Hospital during the time of the study.

The study included conceived women either primigravidae or multigravidae submitted to elective Abdominal Delivery; estimatimation the loss of blood intra- operative and postoperatively in cases injected by Oxytocin versus Tranexamic acid combined with Ethamsylate.

The selected candidates were established into two collections: the first injected by Oxytocin 5 IU infusion on 500 cc saline $0.9 \%$, at rate of $100 \mathrm{~cm} /$ hour before the start of the skin incision , and the second was injected by 1gram of tranexamic acid and $250 \mathrm{mg}$ of ethamsylate IV slowly 5-10 minutes before the start of the skin incision. Too.

Patients included in the study were aged from 20 to 40 years, delivered by Cesarean Delivery (LSCS) and Fetal Gestational age was 38 to 41 weeks. With suitable history, suitable general and local exams and accepted pregnant Doppler ultrasound and suitable laboratory results. Except the ones who had side effects to the medications prepared for this research, anaemic patients, polyhydraminos, multi fetal pregnancy, patients with fibroid uterus, patients with hemorrhagic tendency or coagulative abnormalities. And the conditions related to abnormal placentae. (Placental abnormalities).

As regard to the distribution of the candidates either primigravidae or multigravidae between both groups nearly equal distributed.

All the tested candidates were delivered by Elective abdominal delivery with suturing of the uterus into two layers inside the abdomen; spinal anesthesia was applied to all of them through the Lower Segment Cesarean Section utilized by a classic procedural approach and all the deliveries were done by one surgical team.

All participants were observed intra-operatively and post-operatively by close watching of the vital marks as blood pressure and heart rate, volume of urine inside the catheter and contractility of the uterus.

The chief aim results of this study was the amount of hemorrhage occurrence during the operation, and It was calculated by two variants, the primary mean was calculated by the variation between the weight of dry towels and the weight of wet towels with blood and any other liquids were suctioned out early before the usage of the towels. Another way, difference of the hemoglobin values before and after the procedure, also the Hematocrit percentage before the procedure and 24 hours later the procedure.

Secondary results were the percentage of participants whom progressed post-delivery bleeding and requirement for blood transfusion.

\section{Statistical analysis:}

IBM SPSS statistics (Statistical Package for Social Sciences) software version 22.0, IBM Corp., Chicago, USA, 2013 and Microsoft Office Excel 2007. Computer program was designed for accounting the sample size, the statistical calculator based on $95 \%$ of confidence interval and the power of the study is $80 \%$ with $\alpha$ - error 5 . The level of significance was taken at $\mathrm{P}$ value $<0.050$ is significant, otherwise is non-significant. Effect size was calculated to compare Tranexamic acid and ethamsylate group relatively to Oxytocin group using Mean \pm SE for quantitative variables and relative risk for qualitative variables.

\section{RESULTS}

From the measured variables of the participants of the trial demonstrated:

A-No remarkable variations among the studied candidates related to age, BMI, parity, gestational age and also indications of cesarean section.(Table 1)

Also in the study: 
1-the operation time was non-significant between the two groups.

2-Intra-operative blood loss significantly decreased in the candidates received both Tranexamic acid and Ethamsylat than in the Oxytocin candidates.

3-No noted variations among the studied candidates in concerning to pre-procedure haemoglobin \& hematocrit.

4-Post-procedure hemoglobin\& hematocrit values was significantly higher in the group received both Tranexamic acid and Ethamsylate than in the group of Oxytocin.

5-Haemoglobin \& hematocrit reduction significantly lesser in the group of Tranexamic acid and Ethamsylate than in the group of Oxytocin.

6 - No statistically significance variations as regard to the Postoperative hospital stay duration in both groups. However it was lesser in the group of Tranexamic acid and Ethamsylate than in the group of Oxytocin . (Table 2)

\begin{tabular}{|c|c|c|c|c|}
\hline \multicolumn{2}{|c|}{ Variables } & $\begin{array}{l}\text { Tranexamic acid and } \\
\text { ethamsylate }(\mathrm{N}=100)\end{array}$ & $\begin{array}{l}\text { Oxytocin } \\
(\mathrm{N}=100)\end{array}$ & P-value \\
\hline \multirow{2}{*}{ Age (years) } & Mean \pm SD & $29.0 \pm 4.4$ & $28.4 \pm 4.3$ & \multirow{2}{*}{$\wedge 0.284$} \\
\hline & Range & $20.0-40.0$ & $20.0-40.0$ & \\
\hline \multirow{2}{*}{ BMI $\left(\mathrm{kg} / \mathrm{m}^{2}\right)$} & Mean \pm SD & $26.2 \pm 3.0$ & $28.9 \pm 3.1$ & \multirow{2}{*}{$\wedge 0.207$} \\
\hline & Range & $18.5-29.9$ & $18.5-29.9$ & \\
\hline \multirow{2}{*}{ Parity } & Nulli & $48(48.0 \%)$ & $56(56.0 \%)$ & \multirow{2}{*}{ \#0.258 } \\
\hline & Multi & $52(52.0 \%)$ & $44(44.0 \%)$ & \\
\hline \multirow{2}{*}{ G.Age(weeks) } & Mean \pm SD & $38.86 \pm 0.50$ & $38.91 \pm 0.50$ & \multirow{2}{*}{$\wedge 0.618$} \\
\hline & Range & $38.0-41.0$ & $38.0-41.0$ & \\
\hline \multirow{4}{*}{ 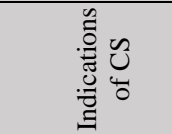 } & Previous CS & $44(44.0 \%)$ & 39 (39.0\%) & \multirow{4}{*}{ \#0.552 } \\
\hline & Maternal request & $29(29.0 \%)$ & $30(30.0 \%)$ & \\
\hline & Malpresentation & $19(19.0 \%)$ & $26(26.0 \%)$ & \\
\hline & Postdate & $8(8.0 \%)$ & $5(5.0 \%)$ & \\
\hline
\end{tabular}

Table 1: Demonstrates the specified components to all candidates as (Age, BMI, Parity, GA and Causes of Abdominal Delivery).

\begin{tabular}{|c|c|c|c|c|}
\hline Measures & $\begin{array}{l}\text { Tranexamic acid and } \\
\text { ethamsylate }(\mathrm{N}=100)\end{array}$ & $\begin{array}{l}\text { Oxytocin } \\
(\mathrm{N}=100)\end{array}$ & P-value & $\begin{array}{l}\frac{\text { Effect size }}{\text { Mean } \pm \text { SE }} \\
95 \% \text { CI }\end{array}$ \\
\hline $\begin{array}{l}\text { Operation duration } \\
\text { (minutes) } \\
\text { Mean } \pm \text { SD } \\
\end{array}$ & $\begin{array}{l}42.8 \pm 9.0 \\
25.0-55.0\end{array}$ & $\begin{array}{l}49.1 \pm 9.9 \\
27.0-60.0\end{array}$ & $\wedge 0.289$ & $\begin{array}{l}-1.4 \pm 1.3 \\
-3.2-1.2\end{array}$ \\
\hline$\frac{\text { Blood loss (mL) }}{\text { Mean } \pm \text { SD }}$ & $\begin{array}{l}407.1 \pm 117.3 \\
243-695.0 \\
\end{array}$ & $\begin{array}{l}614.5 \pm 120.7 \\
412.0-887.0 \\
\end{array}$ & $\wedge<0.001 *$ & $\begin{array}{l}-207.4 \pm 16.8 \\
-240.5--174.2 \\
\end{array}$ \\
\hline$\frac{\text { Preoperative } \mathrm{Hb}(\mathrm{gm} / \mathrm{dl})}{\text { Mean } \pm \mathrm{SD}}$ & $\begin{array}{l}10.7 \pm 0.8 \\
10.0-12.6\end{array}$ & $\begin{array}{l}10.8 \pm 0.8 \\
10.0-12.5\end{array}$ & $\wedge 0.287$ & $\begin{array}{l}-0.1 \pm 0.1 \\
-0.3-0.1\end{array}$ \\
\hline $\begin{array}{l}\text { Postoperative } \mathrm{Hb}(\mathrm{gm} / \mathrm{dl}) \\
\text { Mean } \pm \text { SD }\end{array}$ & $\begin{array}{l}10.2 \pm 0.9 \\
9.1-12.1\end{array}$ & $\begin{array}{l}9.9 \pm 0.8 \\
8.9-11.9\end{array}$ & $\wedge 0.032 *$ & $\begin{array}{l}0.3 \pm 0.1 \\
0.0-0.5\end{array}$ \\
\hline$\frac{\text { Reduction }}{\text { Mean } \pm \text { SD }}$ & $\begin{array}{l}0.5 \pm 0.2 \\
0.2-1.2 \\
\end{array}$ & $\begin{array}{l}0.9 \pm 0.2 \\
0.6-1.3\end{array}$ & $\wedge<0.001 *$ & $\begin{array}{l}-0.4 \pm 0.0 \\
-0.5-0.3\end{array}$ \\
\hline $\begin{array}{l}\text { Preoperation HCT\% } \\
\text { Mean } \pm \text { SD }\end{array}$ & $\begin{array}{l}31.0 \pm 2.5 \\
27.2-36.9 \\
\end{array}$ & $\begin{array}{l}31.4 \pm 2.5 \\
27.3-37.0\end{array}$ & $\wedge 0.285$ & $\begin{array}{l}-0.4 \pm 0.4 \\
-1.1-0.3 \\
\end{array}$ \\
\hline $\begin{array}{l}\text { Postoperation HCT\% } \\
\text { Mean } \pm \text { SD }\end{array}$ & $\begin{array}{l}29.5 \pm 2.7 \\
25.3-37.5 \\
\end{array}$ & $\begin{array}{l}30.6 \pm 2.12 \\
24.6-35.9 \\
\end{array}$ & $\wedge 0.027 *$ & $\begin{array}{l}0.8 \pm 0.4 \\
0.1-1.5 \\
\end{array}$ \\
\hline$\frac{\text { Reduction }}{\text { Mean } \pm \text { SD }}$ & $\begin{array}{l}1.5 \pm 1.4 \\
1.9-5.3\end{array}$ & $\begin{array}{l}2.57 \pm 1.6 \\
1.0-6.8 \\
\end{array}$ & $\wedge<0.001^{*}$ & $\begin{array}{l}-1.2 \pm 0.2 \\
-1.6-0.8\end{array}$ \\
\hline $\begin{array}{l}\text { Hospital stay (hours) } \\
\text { Mean } \pm \text { SD }\end{array}$ & $\begin{array}{l}11.9 \pm 0.7 \\
9.0-13.0\end{array}$ & $\begin{array}{l}12.3 \pm 1.1 \\
11.0-15.0\end{array}$ & $\wedge 0.055$ & $\begin{array}{c}-0.2 \pm 0.1 \\
-0.4-0.1\end{array}$ \\
\hline
\end{tabular}

Table 2: Comparison regarding operation duration, blood loss, hemoglobin, hematocrit(pre and post operative) and postoperative hospital stay.
And also, 1- The number of candidates received Blood transfusion were significantly fewer in the candidates received both Tranexamic acid and ethamsylate than in Oxytocin candidates.

2- No statistically significance variations as regard to Intra-operative adhesion, Postoperative fever and Postoperative infection in both groups, however it was lesser in the candidates received Oxytocin than in Tranexamic acid and ethamsylate candidates.

3- No statistically significant difference among all participants as regard to the incidence of Postpartum Hemorrhage.

4- It was obvious that the candidates who faced bleeding in the first group thorough the caesarean birth were 3 patients which represented 3\%. And 6 women bleeded during the operation in the second group which represented 6\%. (Table 3) 


\section{DISCUSSION}

Abdominal Delivery(LSCS) known as caesarean delivery OR caesarean Birth which is about extraction of a fetus or multi fetuses via surgical incision made along the abdominal anterior wall (known as laparotomy) and incision of the lower segment of the uterus.

Recently it is the utmost favorite procedure done in the United States, where as every year greater than one million conceived women delivered by cesarean operation. And the rate of cesarean delivery is raised from $5 \%$ in 1970 to $31.9 \%$ in $2016 .{ }^{13}$

This was a randomized controlled trial, comparing oxytocin alone versus Tranexamic acid and Ethamsylate to reduce blood loss Intra-operative and postoperative during Elective Cesarean Delivery. The study recruited 200 gravid women divided into 2 equal collections.

The current study revealed that there is No significant difference between the studied groups regarding age, BMI, parity, gestational age, and indications of cesarean section. Which was supported by study of (Alanwar \& Gamal, 2020) ${ }^{14}$ as they reported that there was no significant difference as regard patient characteristics (age, weight, BMI, and gestational age) between study and control groups.

Furthermore, (Torky et al., 2020) ${ }^{15}$ demonstrated that there was no significant difference between the studied groups regarding age, BMI, parity and previous cesarean section. Each group contained 60 women the first group received $1 \mathrm{~g}$ of tranexamic acid, while the second received $1 \mathrm{~g}$ of ethamsylate and the third received $10 \mathrm{~mL}$ of normal saline given 20 min before the procedure.

The present study showed that the Operation duration was shorter in Tranexamic acid group and ethamsylate than in Oxytocin group.

The current results were supported by study of (Suryakumari \& Parveen, 2017) $^{16}$ as they revealed that mean time taken for LSCS was $40 \pm 5$ minutes for study groups and $45 \pm 5$ minutes for control group with significantly significant difference between them. They were randomly divided into 3 groups of 30 women each, study groups, which included AT who received tranexamic acid and AE who received ethamsylate and control group AN who received normal saline.

The current results were supported by study of (Torky et al., 2020) ${ }^{15}$ as they reported that both tranexamic acid and ethamsylate are associated with significantly lower mean blood loss, lower need for blood transfusion and lower need for additional interventions to decrease blood loss than placebo group. While postoperative hemoglobin and hematocrit were significantly higher in both tranexamic acid and ethamsylate as compared to placebo, although the effect was more in the tranexamic acid group than the ethamsylate group in all parameters suggesting that tranexamic acid is superior to ethamsylate in reducing blood loss, decreasing the need for blood transfusion, and higher postoperative hemoglobin and hematocrit, however, tranexamic acid was associated with higher risk of side-effects than ethamsylate namely nausea and vomiting.

(Bhatia \& Deshpande, 2015) ${ }^{17}$ Studies have shown that tranexamic acid is effective in reducing blood loss during elective cesarean section and this is consistent with the recommendations of The Royal College of Obstetricians \& Gynecologists (RCOG., 2018) $)^{18}$.

In the study of (Suryakuman and Parveen, 2017) ${ }^{16}$ compared the effect of ethamsylate with tranexamic acid and placebo in reducing blood loss during elective cesarean section and concluded that both drugs were more effective in reducing blood loss than placebo, but the effect was more in the tranexamic acid group.

According to (Alanwar \& Gamal, 2020) ${ }^{14}$ they demonstrated that intraoperative intravenous administration of tranexamic acid together with ethamsylate given just after delivery of the fetus is an effective method for reduction of blood loss during elective lower-segment cesarean delivery. Furthermore, tranexamic acid and ethamsylate reduce the need for ecbolic drugs during the postoperative period and reduces the postpartum blood loss in patients with high risk for postpartum hemorrhage.

\section{CONCLUSION}

The current results demonstrated that tranexamic acid and ethamsylate can be used safely to reduce bleeding during and after CS. Tranexamic acid and ethamsylate appear to be a safe and effective option in the treatment of obstetric hemorrhage

Further researches with large numbers of patients with different dosage and administration routes are preferable to compare the efficacy of each route.

\section{REFERENCES}

1. Betran AP, Torloni MR, Zhang JJ et al. WHO Statement on Caesarean Section Rates. BJOG. 2016; 123: 667-70.

2. U.S. Department of Health and Human Service: 1 February. Archived from the original on 28 July 2017. Retrieved 15 July 2017.

3. WHO: Statement on Caesarean Section Rates. Archived from the original on 1 May 2015. Retrieved 6 May 2015.

4. Sathe NA, Likis FE, Young JL, et al. Procedures and Uterine-Sparing Surgeries for Managing Postpartum Hemorrhage: A Systematic Review. Obstet.Gynecol Surv. 2016; 71(2): 99-113. 
5. Hernández-Castro F, López-Serna N, TreviñoSalinas EM, et al. Randomized doubleblind placebo-controlled trial of buccal misoprostol to reduce the need for additional uterotonic drugs during Abdominal Delivery. Int $J$ Gynecol Obstet. 2016;132:184-7.

6. Wang HY, Hong SK, Duan Y, et al. Tranexamic acid and blood loss during and after caesarean section: a meta-analysis. $J$ Perinatol. 2015;35(10):818-25.

7. RCOG. Postpartum haemorrhage, Prevention and Management. Green-top Guideline. No. 52. 2016.

8. Law RH, Wu G, Leung EW, et al. X-ray crystal structure of plasmin with tranexamic acid-derived active site inhibitors. Blood Advances. 2017;1 (12): 766-71.

9. Wu G, Mazzitelli BA, Quek AJ, et al. Tranexamic acid is an active site Inhibitor of urokinase plasminogen activator. Blood Advances. 2019; 3(5):729-33.

10. Suryakumari, B and Parveen, S. A comparative study of tranexamic acid versus ethamsylate used prophylactically in lower segment caesarean section A prospective randomised double blinded study. J Evid Based Med Health. 2017;4:4435:8.

11. Abdel-Salam, O. M. E., Shaffie, N. M and Sleem, A. A. Ethamsylate Protects Against the Carbon Tetrachloride-Induced Liver Damage in Rats. $J$ Diabetes Metab Disord Control. 2017; 4(3), 109.

12. Fatah, A. T. A., El-Mohandes, M. I and ElMadany, Y. A. Tranexamic Acid and Ethamsylate for Reducing Blood Loss in Patient Undergoing LSCS at High Risk for Postpartum Hemorrhage. The Egyptian Journal of Hospital Medicine . 2018, 73(4), 6452-6.

13. ACOG: American Congress of Obstetricians and Gynecologists and the Society for Maternal-Fetal Medicine. March 2019.

14. Alanwar, A. and Gamal, M.M. Tranexamic Acid and Ethamsylate for Reducing Blood Loss in Patient Undergoing Lower Segment Cesarean Section at High Risk for Post-Partum Hemorrhage: A Pilot Study. Open Journal of Obstetrics and Gynecology. 2020; 10, 1340-1350. https://doi.org/10.4236/ojog.2020.1090123

15. Torky, H., El-Desouky, E. S., Abo-Elmagd, I., et al. Pre-operative tranexemic acid vs. etamsylate in reducing blood loss during elective cesarean section: randomized controlled trial. Journal of Perinatal Medicine. 2021; 1(ahead-of-print).

16. Suryakumari, B and Parveen, S. A comparative study of tranexamic acid vs. ethamsylate used prophylactically in lower segment caesarean section-a prospective randomized double-blinded study. J Evid Based Med Healthc. 2017; 4, 44358.

17. Bhatia SK and Deshpande H. Role of tranexamic acid in reducing blood loss during and after cesarean section. Med $J$ DY Patil Univ. 2015;8:21-5.

18. RCOG. Prevention and management of postpartum haemorrhage. Green-top Guidelines no. 52. London: Royal College of Obstetricians and Gynecologists. 2009.updated 2018. 